\title{
Rupture process and coseismic deformations of the 27 February 2010 Maule earthquake, Chile
}

\author{
Nelson Pulido ${ }^{1}$, Yuji Yagi ${ }^{2}$, Hiroyuki Kumagai ${ }^{1}$, and Naoki Nishimura ${ }^{2}$ \\ ${ }^{1}$ National Research Institute for Earth Science and Disaster Prevention, 3-1 Tennodai, Tsukuba, Ibaraki 305-0006, Japan \\ ${ }^{2}$ University of Tsukuba, 1-1-1 Tennodai, Tsukuba, Ibaraki 305-8572, Japan \\ (Received January 7, 2011; Revised April 26, 2011; Accepted April 26, 2011; Online published December 29, 2011)
}

\begin{abstract}
We estimated the spatial and temporal slip distribution for the 27 February 2010 Maule earthquake from teleseismic body wave data. To obtain a stable inversion solution, we used the data covariance matrix from the observation and modeling errors, incorporated smoothing constraints and determined their optimal values by using the Akaike Bayesian Information Criterion (ABIC). The fault rupture can be divided into three stages. For the first $30 \mathrm{~s}$ the rupture started as an elliptical crack elongated in the in-plane direction along the dip. After $30 \mathrm{~s}$ the rupture propagated bi-laterally along strike reaching the maximum moment release rate at around $50 \mathrm{~s}$ near the hypocenter. Finally the rupture propagated mainly to the north reaching another peak of moment release rate at $80 \mathrm{~s}$ and $130 \mathrm{~km}$ north-east from the hypocenter. Main rupture lasted for about $110 \mathrm{~s}$. In order to evaluate our source model, we calculated the predicted coseismic vertical displacements and compare them with observed uplift/subsidence values measured along the coastline, as well as displacements obtained from strong ground motion and high-sampling GPS records in Concepción. Our model provides good estimations of the static displacements in the northern source region, but under-estimates the coseismic uplifts in the southern region.
\end{abstract}

Key words: 2010 Chile earthquake, source process, permanent displacement, strong motion.

\section{Introduction}

On 27 February 2010, central Chile was heavely hit by a mega-earthquake $\left(M_{\mathrm{w}} 8.8,06: 34: 14 \mathrm{UTC}, 72.733 \mathrm{~W}\right.$, 35.909S; USGS, 2010), causing extensive damage in Concepción and Santiago cities. This event, the sixth largest earthquake in instrumental history, was located in the Meridional Andes beneath the South American plate, where the Nazca plate converges at a rate of $6.5 \mathrm{~cm} /$ year. This earthquake filled well studied seismic gap between the 1960 Great Valdivia earthquake $\left(M_{\mathrm{w}} 9.5\right)$ and the 1985 Valparaiso earthquake $\left(M_{\mathrm{s}} 7.8\right)$ (Barrientos and Ward, 1990; Ruegg et al., 2009; Fig. 1). Interseismic strain accumulation measurements indicated that the ConcepciónConstitución area was a mature seismic gap (Campos et al., 2002; Ruegg et al., 2009), which overlaps the rupture area of the great 1835 earthquake. In this study we investigate the rupture process of the Maule earthquake based on an inversion of teleseismic body waves recorded by the Global Seismic Network. We use the new inversion approach of Yagi and Fukahata (2011), in which correlated errors originated from uncertainty of Green's functions are incorporated to reduce the bias of inversion results. Then, using our source model we calculate the vertical deformations and compare them with uplift/subsidence values measured along the coast from the Arauco Peninsula to Viña del Mar covering the entire source area (Farías et al., 2010). The

Copyright (c) The Society of Geomagnetism and Earth, Planetary and Space Sciences (SGEPSS); The Seismological Society of Japan; The Volcanological Society of Japan; The Geodetic Society of Japan; The Japanese Society for Planetary Sciences; TERRAPUB.

doi:10.5047/eps.2011.04.008 observed deformations along the coast clearly indicated the hinge line along the fault strike where seaward uplift turns into landward subsidence. We use these data to evaluate the slip distribution of the Maule earthquake estimated from the seismic inversion. We also calculate the static displacement at Concepción from our source model, and compare it with the ones obtained from strong ground motion and high-sampling GPS records at this city.

\section{Data}

We retrieved teleseismic body-wave data (38 $P$ waves) with a good azimuthal coverage from the IRIS-DMC web site (http://www.iris.edu). These teleseismic body waves were integrated into ground displacements, and decimated with a sampling period of 1.5 seconds. We applied an antialiasing Butterworth low pass filter before the re-sampling. Surface waves may produce large off-diagonal components in the data covariance matrix, which can not be treated in the inversion approach of Yagi and Fukahata (2011).

To evaluate our model, we used 28 observed uplift/subsidence data along the coast and estuarine valleys (Farías et al., 2010). Coastal uplift was estimated by measurements of a white fringe formed by dead coralline crustose algae raised above the lower intertidal zone, and subsidence was measured based on inundated constructions and vegetation (Farías et al., 2010). We also used a strong motion digital recording at Concepción (CCSP station), belonging to the strong motion network of the Seismological Service (SSN), Universidad de Chile (Barrientos, 2010). Using this record we obtained the permanent displacement at Concepción. Finally we compare the displacement es- 


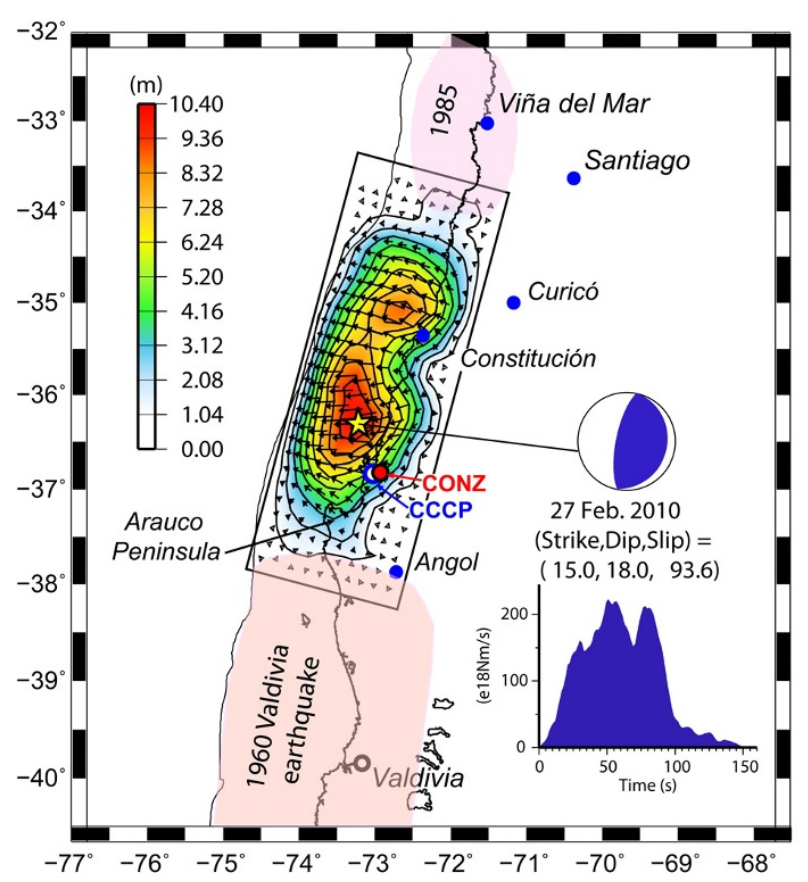

Fig. 1. Source model of the 27 February 2010 Maule earthquake, Chile. Color scale represents the slip amplitude and arrows the slip direction. Our CMT solution of the earthquake is shown. The moment rate function of the earthquake is displayed in the inset. Approximate source areas of the 1960 and 1985 earthquakes are shown (Barrientos and Ward, 1990; Campos et al., 2002).

timated from the strong ground motion record with those from a high-sampling GPS record at station CONZ located $9 \mathrm{~km}$ west of CCSP in the Transportable Integrated Geodetic Observatory (TIGO) (Sierk and Hase, 2010), which is jointly operated by the Universidad de Concepción and the German Federal Agency for Cartography and Geodesy (BKG).

\section{Teleseismic Inversion and Fault Model}

To investigate the rupture process of the Maule earthquake, we used a multitime window inversion scheme that incorporates the data covariance matrix from the observation and modeling errors (Yagi and Fukahata, 2011), and the Akaike Bayesian Information Criteria (ABIC) for optimum estimations of smoothness constraint parameters (Yagi and Fukahata, 2008). The Yagi and Fukahata (2011) inversion approach incorporates correlated errors that originate from uncertainty of Green's functions, to reduce the bias of inversion results. In this technique slip rate distribution on the assumed fault plane is represented as a linear combination of basis functions in space and time. For the Maule earthquake the basis functions of slip rate in space were obtained using B-splines, and $27 \times 10$ knots distributed with an uniform interval of $18 \mathrm{~km}$ across the fault plane. The slip time history of each knot was represented by overlapping triangle functions interpolated with linear B-splines with an interval of $1.5 \mathrm{~s}$, allowing a maximum rise time of $60 \mathrm{~s}$. In order to obtain a stable solution, we applied smoothness constraints with respect to time, the spatial distribution of slip, and the rake angle. The optimum smoothness parameters were estimated by finding the minimum value of ABIC.
Table 1. Velocity model.

\begin{tabular}{cccc}
\hline $\begin{array}{c}\mathrm{Vp} \\
(\mathrm{km} / \mathrm{s})\end{array}$ & $\begin{array}{c}\mathrm{Vs} \\
(\mathrm{km} / \mathrm{s})\end{array}$ & $\begin{array}{c}\text { Density } \\
\left(\times 10^{3} \mathrm{~kg} / \mathrm{m}^{3}\right)\end{array}$ & $\begin{array}{c}\text { Thickness } \\
(\mathrm{km})\end{array}$ \\
\hline 1.50 & 0.00 & 1.02 & 1.0 \\
5.51 & 3.19 & 2.60 & 4.0 \\
6.28 & 3.60 & 2.70 & 15.0 \\
6.89 & 3.93 & 2.90 & 15.0 \\
7.40 & 4.12 & 3.10 & 10.0 \\
7.76 & 4.55 & 3.20 & 10.0 \\
7.94 & 4.55 & 3.30 & 0.0 \\
\hline
\end{tabular}

In Table 1 we show the 1-D structural velocity model used for calculating the Green functions (Bohm et al., 2002). We added an ocean layer with $1-\mathrm{km}$ thickness to model water reverberations in teleseismic waveforms. The thickness of this layer was estimated by trial and error to optimize the fits to inverted data.

Our fault model has a length of $486 \mathrm{~km}$ along strike and a width of $180 \mathrm{~km}$ along dip. We used the epicenter estimated by SSN (73.239W, 36.290S), which is located about $62 \mathrm{~km}$ south-west of the USGS hypocenter. The fault geometry for inversion (strike $15^{\circ}$ and dip $18^{\circ}$ ) was estimated by slightly modifying the $\mathrm{gCMT}$ solution (strike $18^{\circ}$ and dip $18^{\circ}$ ) based on fit to teleseismic waveforms. The starting time of rupture at each space knot was evaluated by its distance to the hypocenter and the rupture front velocity. Based on our preliminary analysis, we determined the rupture front velocity and the depth of hypocenter to be $2.8 \mathrm{~km} / \mathrm{s}$ and $34 \mathrm{~km}$, respectively.

\section{Source Rupture Process}

The Maule earthquake ruptured a source area of nearly $400 \mathrm{~km}$ extending along strike from the Arauco Peninsula to southern Santiago (Fig. 1). Our solution indicates an average rake angle of $93.5^{\circ}$ and a seismic moment of $1.48 \mathrm{e} 22 \mathrm{~N} \mathrm{~m}\left(M_{\mathrm{w}} 8.7\right)$. This value is slightly smaller than the gCMT solution $\left(M_{\mathrm{w}} 8.8\right)$, but it is within the typical error range in teleseismic inversions, due to differences in the velocity model (Yagi et al., 2004). The source process is characterized by two asperities with peak slip of about $10 \mathrm{~m}$ and a rupture area of approximately $400 \mathrm{~km} \times 140 \mathrm{~km}$. The first and largest asperity is located around the hypocenter and the second is located approximately $135 \mathrm{~km}$ northeast of the hypocenter. The largest moment release is located seaward in a region near to the coastline (Fig. 1). In Fig. 2 we plot the sequence of the rupture for the average slip velocity in each 10 -s window. We can observe that for the first $30 \mathrm{~s}$ the rupture started in the in-plane direction along the dip. After $30 \mathrm{~s}$ the rupture started propagating bi-laterally along the fault strike. The first major moment release episode for this earthquake occurred at around $50 \mathrm{~s}$, near the hypocenter, followed by a comparable moment release event at $80 \mathrm{~s}$ located $130 \mathrm{~km}$ north-east of the hypocenter (Fig. 2). Main rupture lasted for about $110 \mathrm{~s}$. These features of the rupture are also observed in the source time function of the earthquake (inset in Fig. 1). The aver- 

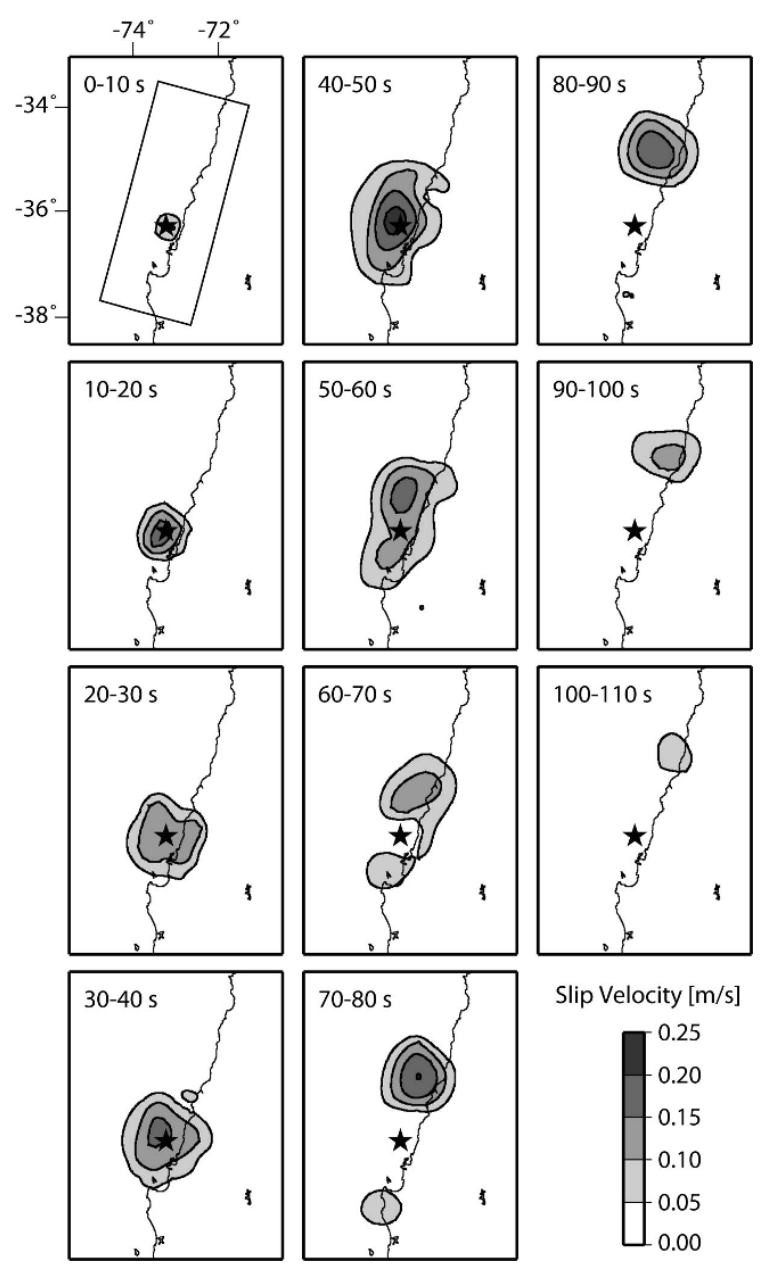

Slip Velocity $[\mathrm{m} / \mathrm{s}]$

0.25
0.20
0.15
0.10
0.05
0.00

Fig. 2. Snapshots of slip velocity (gray scale) depicting the fault rupture of the Maule earthquake in every 10-s window.

age rake angle of this model is $93^{\circ}$, which implies a difference of approximately $18^{\circ}$ with respect to the convergence direction of the Nazca plate beneath the South American plate (DeMets et al., 2010). The northern propagation of our rupture model also indicates a clockwise rotation of $10^{\circ}$ with respect to the fault strike as can be observed in the snapshots of slip velocity after $90 \mathrm{~s}$. Figure 3 displays waveform fits between observations (black) and simulations (gray). We obtained a L2 norm misfit value of 0.17 , which we consider a good fit. The inversion methodology used in this study is little influenced by changes in the velocity structure and fault dip (Yagi et al., 2004). The hypocenter location (or origin time) may only affect the relative location of slip (Yagi et al., 2004).

\section{Coseismic Permanent Displacements}

In order to evaluate our source model obtained from the teleseismic waveform inversion, we used the elastic dislocation model of Okada (1992) to calculate the modelpredicted coseismic vertical displacements along the coastline as well as in a region around the source area of the Maule earthquake (Figs. 4 and 5). The distribution of the vertical displacements at the surface ressembles the shape of the slip distribution, but slightly shifted to north-west due to the fault geometry. The largest values of uplift and
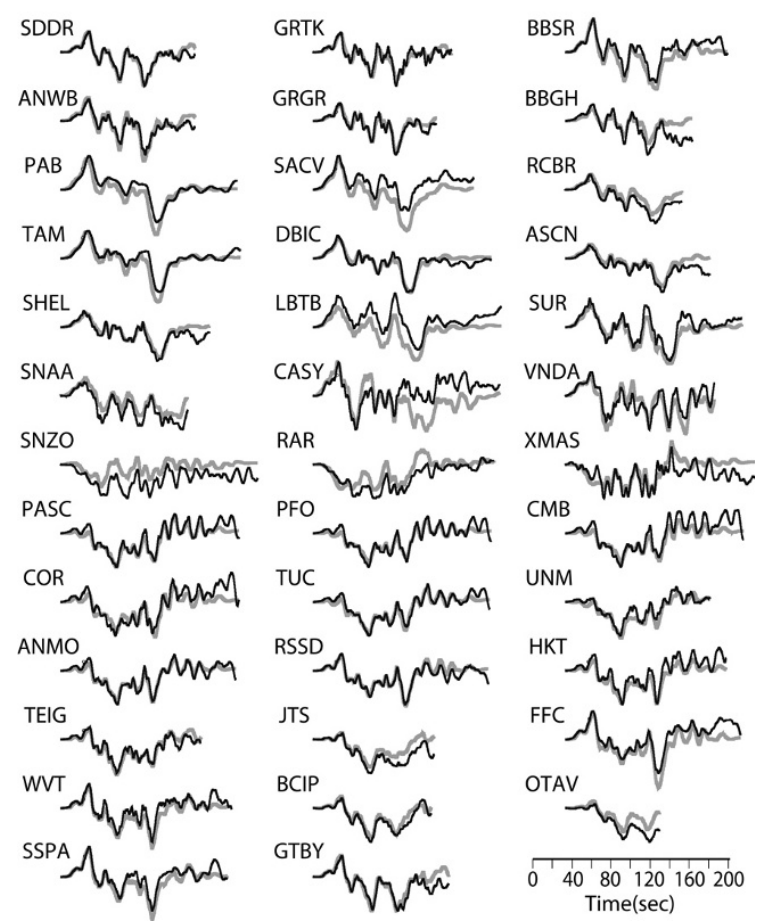

Fig. 3. Waveform fits between vertical observed (black) and simulated (gray) teleseismic $P$ waveforms of the Maule earthquake.

subsidence reach $3 \mathrm{~m}$ and $1 \mathrm{~m}$, respectively. Our model predicts a transition from uplift to subsidence (hinge line) near the coastline (Fig. 4). Observed uplift/subsidence values (Farías et al., 2010) are small in the region north of the epicenter (33.5-36S), which is in agreement with the values predicted by our model (Fig. 5(A)). In the southern portion of the rupture (36.5-38S), the observed values of coastal deformation indicate uplift of about $50 \mathrm{~cm}$ in Talcahuano (points 11, 12 and 13 in Fig. 5(A)), and a larger uplift up to $2.5 \mathrm{~m}$ in the Arauco Peninsula (points 15 and 19 to 26 in Fig. 5(A)). Although our model predicts uplift in this region, the average of the estimated values are nearly two times smaller than the observed ones. This discrepancy suggests that larger fault slip beneath the Arauco Peninsula than the one estimated from our slip model is required to explain the observed uplift in this region. A cross section of the uplift/subsidence values normal to the coast shows that observed values are larger in the region closer to the trench and gradually decrease with increasing distance from the trench (Fig. 5(B)). Simulated values of uplift/subsidence for two cross sections along the southern and northern asperities, as well as the average values of uplift/subsidence for the entire fault show a similar trend (Fig. 5(B)). GPS measurements for the Maule earthquake indicate a westward coseismic displacement of $3.0 \mathrm{~m}$ at station CONZ in Concepción (Sierk and Hase, 2010). We calculated the permanent displacement at Concepción using the strong motion record of the earthquake at station CCSP, which is located approximately $8 \mathrm{~km}$ away from CONZ. For this purpose we first integrated the unfiltered acceleration waveform to obtain the velocity waveform (Fig. 6(A)). To correct the velocity waveform we fitted a straight line to 


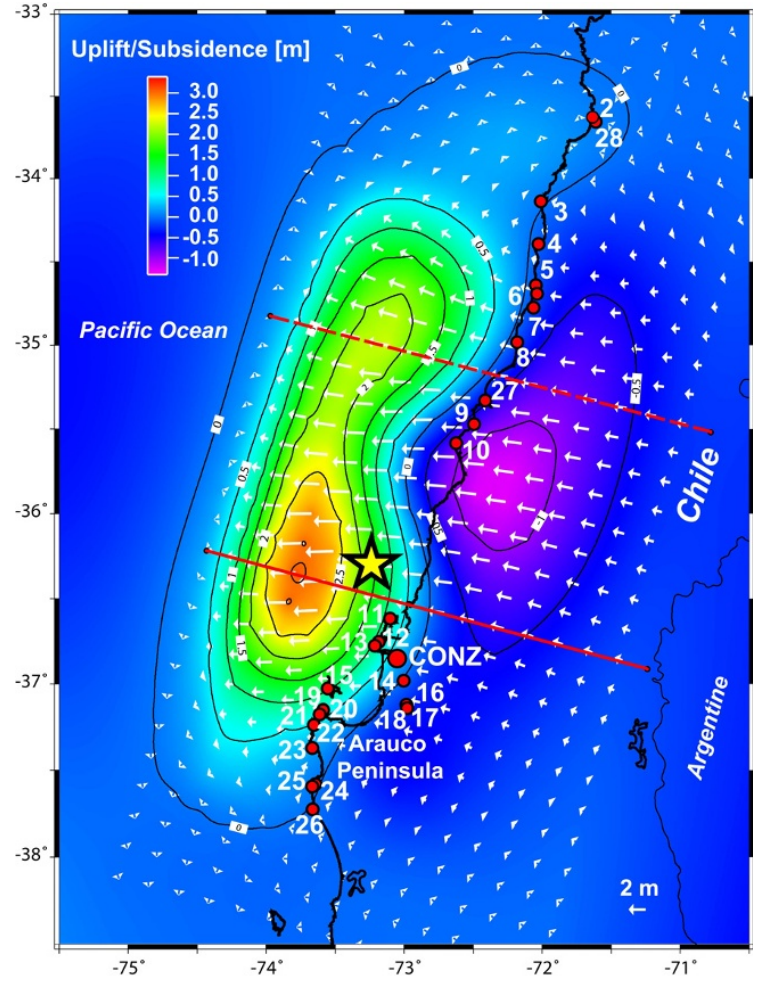

Fig. 4. Static displacements estimated from our source model of the Maule earthquake. Contours with colors and white arrows indicate the vertical and horizontal displacements, respectively. Red dots show the measurement points of land level changes along the coast (Farías et al., 2010). Red lines indicate the locations of cross sections for vertical displacements in Fig. 5(B).
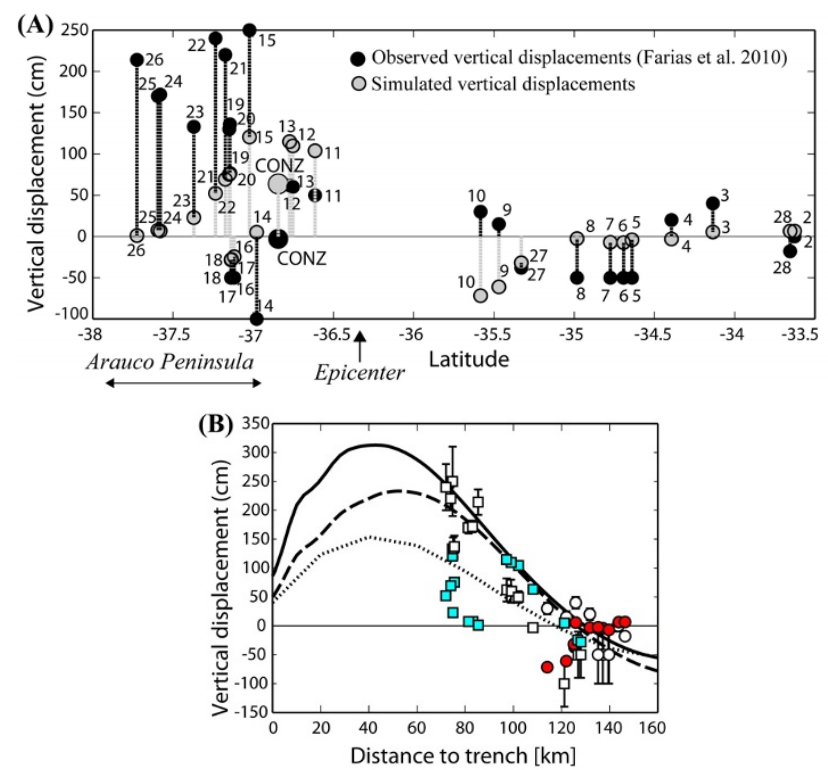

Fig. 5. (A) Comparison between observed (black dots) and simulated (gray dots) coseismic vertical displacements along the coast associated with the Maule earthquake. The numbers near the dots indicate the locations of measurement points shown in Fig. 4. (B) Cross section for observed data and simulations in Fig. 5(A) as a function of their distance from the trench. Red circles and blue squares depict simulation points north and south of the epicenter respectively. Open circles and squares depict observed data north and south of the epicenter respectively. The data are plotted with error bars (Farías et al., 2010). Cross sections of average vertical displacement for the entire fault (dotted line), the southern asperity (solid line), and the northern asperity (dashed line) are shown (see Fig. 4 for the locations of the cross sections).

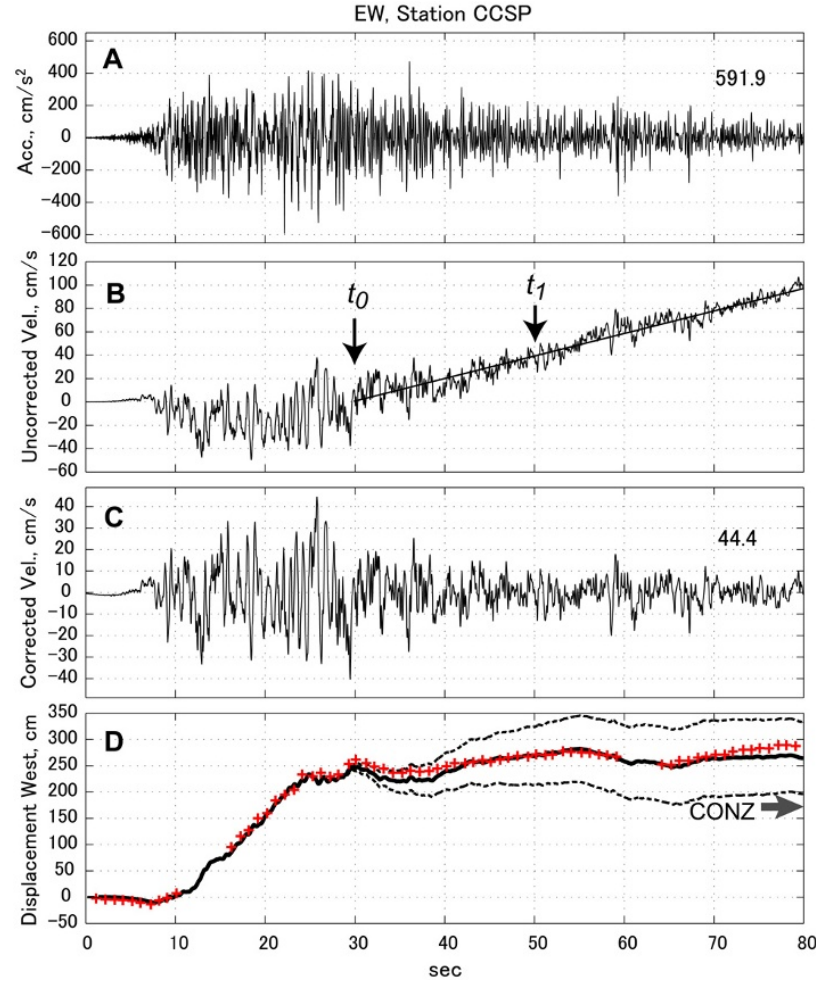

Fig. 6. (A) Unfiltered acceleration record of the Maule earthquake at station CCSP in Concepción. (B) Uncorrected velocity waveform obtained from the integration of the acceleration record in Fig. 6(A). (C) De-trended velocity waveform. (D) Displacement waveform (solid line) obtained from the integration of the de-trended velocity waveform. The dashed lines indicate the estimation errors. The red crosses show the high-sampling GPS dis-placement record at station CONZ. The gray arrow indicates the static displacement estimated from our source model.

an observed trend from an arbitrary point $t_{1}$ within the trend to the end of the waveform window (80 s) (Fig. 6(B)). Then we evaluated the point $t_{0}$ where the fitted line crosses the zero axis. We substracted the fitted values in the interval between $t_{0}$ and $80 \mathrm{~s}$ to obtain the de-trended velocity waveform (Fig. 6(C)), which we integrated in time to obtain the displacement waveform. We repeated this procedure varying $t_{1}$ every second from 20 to $60 \mathrm{~s}$ to obtain the errors in our estimation of the displacement waveform (Fig. 6(D)). The corrected displacement waveform shows a remarkable match with the high-sampling GPS displacement record at CONZ (Fig. 6(D)). The estimated value of vertical offset at CONZ from our model is slightly smaller than the observed value (arrow in Fig. 6(D)).

\section{Discussion}

The main slip in our source model is located in a region near the coastline, around the hypocenter. This feature is in good agreement with the source model of Delouis et al. (2010), but differs from the source model of Lay et al. (2010), in which the main moment release is located near the trench. A recent tomographic study conducted in the source area of the Maule earthquake suggests the updip limit of the rupture zone to be located $30-40 \mathrm{~km}$ away from the trench (Contreras-Reyes et al., 2010). This limit is defined by the presence of a $20-40 \mathrm{~km}$ wide sedimentary wedge above the subducting plate, which would behave 
aseismically due to the presence of high-porosity fluid-rich sediments (Contreras-Reyes et al., 2010). The source model of Lay et al. (2010) would imply that the majority of slip occurred in this aseismic zone. On the other hand, the high-frequency radiated seismic energy suggests that the Maule earthquake may be identified as a normal megathrust event, namely an earthquake whose rupture does not extend to the near-trench region (Newman and Convers, 2010), supporting the rupture near the coast as indicated by our source model.

The underestimation of uplift in the Arauco Peninsula may suggest that the southern rupture is not well resolved by our model. The source models of Lay et al. (2010) and Delouis et al. (2010) also display small slip in this region, suggesting a lack of the resolution for the southern rupture in teleseismic waveform inversions in general. A possible explanation for the large observed uplift values at the Arauco Peninsula as well as the absence of coseismic fault slip obtained from teleseismic inversions beneath the peninsula, could be the occurrence of large post-seismic deformation in the region. However the large concentration of early aftershocks of the Maule earthquake beneath the Peninsula suggests a coseismic fault rupture in this region (Moreno et al., 2010). On the other hand a recently published slip model of the Maule earthquake based on the inversion of geodetic and tsunami data indicates larger slip in the southern region as compared to those from seismological models (Lorito et al., 2011). This difference may indicate different rupture characteristics in the southern and northern regions in which the northern region radiated strong seismic waves, while the southern rupture was characterized by slower rupture processes, inefficient in seismic radiation. This would explain why geodetic data better resolved the southern rupture. Further studies are required to investigate the characteristics of the southern rupture beneath the Arauco Peninsula.

Acknowledgments. We would like to thank Sergio Barrientos and Jaime Campos of the Universidad de Chile for sharing the strong motion data used in this study. The high-sampling GPS data were obtained from the TIGO observatory homepage. This study was partly supported by the SATREPS project "Enhancement of Earthquake and Tsunami Mitigation Technology in Peru". We thank the editor-in-chief Prof. Yomogida as well as two anonymous referees for helpful comments. Teleseismic data was downloaded from the IRIS-DMC web site (http://www.iris.edu), and the gCMT mechanism was obtained from the global CMT project web site (http://www.globalcmt.org).

\section{References}

Barrientos, S., TERREMOTO CAUQUENES 27 FEBRERO 2010, Servicio Sismológico, Universidad de Chile, Informe Técnico Actualizado 27 Mayo 2010, 5/2010a, http://ssn.dgf.uchile.cl/ informes/INFORME_TECNICO.pdf, 2010 (in Spanish).

Barrientos, S. and S. Ward, The 1960 Chile earthquake: Inversion for slip distribution from surface deformation, Geophys. J. Int., 103, 589-598,
1990.

Bohm, M., S. Lüth, H. Echtler, G. Asch, K. Bataille, C. Bruhn, A. Rietbrock, and P. Wigger, The Southern Andes between $36^{\circ}$ and $40^{\circ} \mathrm{S}$ latitude: seismicity and average seismic velocities, Tectonophysics, $\mathbf{3 5 6}$, 275-289, 2002.

Campos, J., D. Hatzfeld, R. Madariaga, G. Lopez, E. Kausel, A. Zollo, G. Iannacone, R. Fromm, S. Barrientos, and H. Lyon-Caen, A seismological study of the 1835 seismic gap in south-central Chile, Phys. Earth Planet. Inter., 132, 177-195, 2002.

Contreras-Reyes, E., R. Flueh, and I. Grevemeyer, Tectonic control on sediment accretion and subduction off south-central Chile: Implications for coseismic rupture processes of the 1960 and 2010 megathrust earthquakes, Tectonics, doi:10.1029/2010TC002734, 2010 (in press).

Delouis, B., J. Nocquet, and M. Vallee, Slip distribution of the February $27,2010 \mathrm{Mw}=8.8$ Maule Earthquake, central Chile, from static and high-rate GPS, InSAR, and broadband teleseismic data, Geophys. Res. Lett., 37, L17305, doi:10.1029/2010GL043899, 2010.

DeMets, C., R. G. Gordon, and D. F. Argus, Geologically recent plate motions, Geophys. J. Int., 181, 1-80, doi:10.1111/j.1365246X.2010.04491.x, 2010.

Farías, M., G. Vargas, A. Tassara, S. Carretier, S. Baize, D. Melnick, and K. Bataille, Land-level changes produced by the Mw 8.82010 Chilean Earthquake, Science, 329, 916, doi:10.1126/science.1192094, 2010.

Lay, T., C. J. Ammon, H. Kanamori, K. D. Koper, O. Sufri, and A. R. Hutko, Teleseismic inversion for rupture process of the 27 February 2010 Chile (Mw 8.8) earthquake, Geophys. Res. Lett., 37, L13301, doi:10.1029/2010GL043379, 2010.

Lorito, S., F. Romano, S. Atzori, X. Tong, A. Avallone, J. McCloskey, M. Cocco, E. Bochi, and A. Piatanesi, Limited overlap between the seismic gap and coseismic slip of the great 2010 Chile earthquake, Nature Geosci., doi:10.1038/NGEO1073, 2011.

Moreno, M., M. Rosenau, and O. Oncken, 2010 Maule earthquake slip correlates with pre-seismic locking of Andean subduction zone, Nature, 467, 198-202, doi:10.1038/nature09349, 2010.

Newman, A. V. and J. A. Convers, Shallow megathrust rupture propagation of some large and giant earth-quakes: Its tsunami potential and identification from spectral energy content, American Geophysical Union, Abstract S52B-062010 presented at 2010 Fall Meeting, AGU, San Francisco, Calif., 13-17 Dec, 2010.

Okada, Y., Internal deformation due to shear and tensile faults in a half space, Bull. Seismol. Soc. Am., 82, 1018-1040, 1992.

Ruegg, J. C., A. Rudloff, C. Vigny, J. B. de Chabalier, J. Campos, E. Kausel, S. Barrientos, and D. Dimitrov, Interseismic strain accumulation measured by GPS in the seismic gap between Concepción-Constitución in Chile, Phys. Earth Planet. Inter., 175, 78-85, 2009.

Sierk, B. and H. Hase, El terremoto de Chile desde la perspectiva científica, Transportable Integrated Geodetic Observatory (TIGO), http://www.tigo.cl/documents/PresDAAD.pdf, 2010 (in Spanish).

USGS, Magnitude 8.8-Offshore Maule, Chile, 2010, http://earthquake. usgs.gov/earthquakes/eqinthenews/2010/us2010tfan/, 2010.

Yagi, Y. and Y. Fukahata, Importance of covariance components in inversion analyses of densely sampled observed data: an application to waveform data inversion for seismic source processes, Geophys. J. Int., 175, 215-221, 2008.

Yagi, Y. and Y. Fukahata, Introduction of uncertainty of Green's function into waveform inversion for seismic source processes, Geophys. J. Int., 186, 711-720, doi:10.1111/j.1365-246X.2011.05043.x, 2011.

Yagi, Y., T. Mikumo, J. Pacheco, and G. Reyes, Source rupture process of the Tecoman, Colima, Mexico Earthquake of 22 January 2003, determined by joint inversion of teleseismic body-wave and near-source data, Bull. Seismol. Soc. Am., 94, 1795-1807, 2004.

N. Pulido (e-mail: nelson@bosai.go.jp), Y. Yagi, H. Kumagai, and N. Nishimura 